A $3^{\text {nd }}$ Revised Manuscript for Journal of Natural Gas Science and Engineering

(Ms. Ref. No.: JNGSE-D-16-00115R3, after language editing)

\title{
Dynamic analysis of a hang-off drilling riser considering internal solitary wave and vessel motion
}

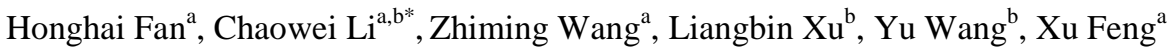

a College of Petroleum Engineering, China University of Petroleum, Changping District, Beijing 102249, China

b Key Lab of Deepwater Engineering, CNOOC Research Institute, Chaoyang District, Beijing 100028, China

\section{Correspondence information:}

Corresponding author: Chaowei Li

Affiliation: $\quad$ College of Petroleum Engineering, China University of Petroleum

Permanent address: Changping District, 102249, Beijing, China

Email address: $\quad$ chw25@163.com (preferred contact channel)

Mobile number: $\quad$ 86-15901422505

Phone number: $\quad$ 86-10-89733221

Fax number: $\quad$ 86-10-89733221 


\title{
Dynamic analysis of a hang-off drilling riser considering internal solitary wave and vessel motion
}

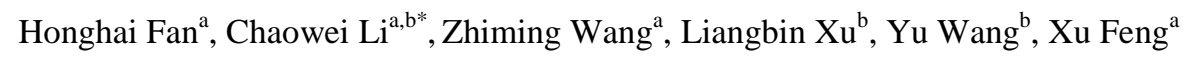 \\ a College of Petroleum Engineering, China University of Petroleum, Changping District, Beijing 102249, China \\ b Key Lab of Deepwater Engineering, CNOOC Research Institute, Chaoyang District, Beijing 100028, China
}

\begin{abstract}
Hang-off mode of a drilling riser is occasionally needed during subsea installation/platform relocation operations or evacuation after an emergency disconnection. A suspending riser without any restriction at its bottom is more flexible and more dangerous in complex sea states than a connected riser with excess axial tension. Internal solitary waves (ISWs) can particularly exert a sudden impact and shearing force on risers, and vessel motion can expand horizontal dynamic responses of the risers. In this paper, considering vessel motion and the combined excitation of ocean currents, surface waves and ISWs, a dynamic model is constructed based on the Euler-Bernoulli theory, in which ISW is simulated by the Korteweg-de Vries (KdV) equation with a two-layer seawater model. Then, the structural governing equation is numerically solved by the Wilson- $\theta$ method and preconditioned generalized minimal residual method (GMRES) with a self-developed MATLAB program. Case calculation shows that ISW can largely increase the envelopes of riser properties in the upper seawater layer and dramatically expand the horizontal deviation of the bottom of a hang-off riser during ISW spreading. Particularly, the dynamic responses of a riser will be larger with ISW amplitude augmentation, and larger with an increase in the density difference between the two seawater layers. In addition, vessel motion can increase the horizontal deviation along the entire length of a riser with a range that is nearly the same as that of the vessel motion amplitude, and increase the envelopes of bending moment and shearing force at the lower section of the riser near the riser bottom. Therefore, limiting the vessel motion amplitude, optimizing the vessel towing speed, maintaining a lower marine riser package (LMRP) at the riser bottom to strengthen axial tension, and using slick joints with larger wall thicknesses in the upper depth may be effective engineering considerations. More importantly, much attention should be paid to avoid the riser bottom/LMRP striking other subsea equipment in oceans in which ISWs occur frequently.
\end{abstract}

Keywords: drilling riser; hang-off mode; internal solitary wave; vessel motion; dynamic envelope.

$\begin{array}{ll}\begin{array}{c}\text { Abbreviations } \\ \text { CNOOC }\end{array} & \text { China National Offshore Oil Corporation } \\ \text { BOP } & \text { blowout preventer } \\ \text { DOF } & \text { degree of freedom } \\ \text { FEM } & \text { finite element method } \\ \text { GMRES } & \text { generalized minimal residual method } \\ \text { iLU } & \text { incomplete LU-decomposition method } \\ \text { ISW } & \text { internal solitary wave } \\ \text { KdV } & \text { Korteweg-de Vries } \\ \text { LMRP } & \text { lower marine riser package } \\ \text { UFJ/LFJ } & \text { upper flex joint/lower flex joint }\end{array}$

\section{Introduction}

Oil and gas resources are rich in oceans, such as the South China Sea, Gulf of Mexico, North Sea and Persian Gulf. To exploit more crude oil and natural gas, offshore floating drilling is a fundamental operation in deepwater. During floating drilling, hang-off mode of a drilling riser is occasionally needed during subsea installation/platform relocation operations, or evacuation after an emergency disconnection (API RP 16Q, 2001). A hang-off riser is suspended under a platform, and its bottom is free from any restriction; accordingly, the platform can only support the entire weight of the riser, but not provide excess top tension to maintain the riser string in a tensional state. Therefore, in harsh sea states, hang-off risers have larger deviations and more drastic dynamic responses than risers fixed on a subsea wellhead. Such riser responses may lead to some of the following issues and dangers:

(1) Difficulty determining the distance between the rise bottom and subsea wellhead during riser installation;

(2) Possible striking of the moon pool or damaging the upper flex joint (UFJ) due to the large rotation and deflection at the riser top;

(3) Undesirable striking between the LMRP and seafloor or between the risers and other subsea equipment due to the large offset or drastic swing at the riser bottom;

(4) Severe fatigue damage at weak points along a riser cause by the large dynamic responses.

Researchers analysed the mechanical behaviours of drilling risers in hang-off mode or during installation. Patel and Jesudasen(1987) presented a theoretical and experimental investigation of the lateral dynamics of free hanging marine risers. Ambrose et al.(2001) and Bybee(2002) discussed the possibilities of using a soft hang-off option and compared the performance characteristics of a drilling riser in soft hang-off and hard hang-off configurations, particularly for ultra-deepwater applications. Dai et al.(2009) analysed the dynamic behaviour of a deepwater drilling riser under hang-off working conditions using ABAQUS software. Williams(2010) discussed optimization of drilling riser operability envelopes for harsh environments, in which the soft/hard riser hang-off configurations for storm events were assessed. Wu et al.(2014) researched the dynamic response of a drilling riser in hard hang-off mode, in which the platform motion as well as wave and current effects were considered. Wang et al.(2014, 2015) studied the static behaviour and lateral vibration of a drilling riser during installation, and considered different hanging weights at the blowout preventers (BOPs). Qi et al.(2015) calculated the evacuation speed range of a hard hang-off drilling riser due to a typhoon using a commercial finite element method (FEM) software, OrcaFlex.

\footnotetext{
* Corresponding author. Tel.: +86 15901422505; E-mail address: chw25@163.com(C. Li).
} 
Normally, vessel motion has six patterns: heave, surge, sway, yaw, roll and pitch. Compared with four other patterns, horizontal deviations (surge and sway) are the two main factors that affect the transverse motion of risers, and both can add the effect of lateral drag force along a riser. Sexton and Agbezuge(1976) researched the influence of both random waves and vessel motion on connected drilling risers. Head et al.(2013) and Royer et al.(2014) evaluated various potential concepts of a steel catenary riser for high-motion vessels operating in ultra-deepwater. Wang et al.(2014, 2015) analysed the out-of-plane vortex-induced vibration of a steel catenary riser caused by vessel motions and evaluated its fatigue damage. Chen et al.(2015) evaluated the impacts of top-end vessel sway on the vortex-induced vibration of a submarine riser for a floating platform in deep water. Iwona et al.(2015) analysed the influence of vessel motion on riser dynamics by the rigid finite element method.

ISWs are another important factor in ocean engineering, and have been a hot topic in recent oceanographic research. Internal waves are gravity waves that oscillate within a fluid medium rather than on its surface. To exist, the fluid must be stratified: the density must decrease continuously or discontinuously with height due to changes, for example, in temperature and/or salinity. If the interfacial waves have large amplitudes, they are called ISWs or internal solitons. In oceans, ISWs are especially common over continental shelf regions and where brackish water overlies salt water at the outlet of large rivers. In fact, ISWs occur frequently and distribute widely in most oceans, such as the Estremadura Promontory off the West Iberian Coast(Magalhaes and Silva, 2012), Mascarene Plateau of the Indian Ocean(New et al., 2013), and northwestern South China Sea(Xu et al., 2016). For example, in the western South China Sea, ISWs have amplitudes of $170 \mathrm{~m}$, half widths of $3 \mathrm{~km}$, and phase speeds of $2.9 \pm$ $0.1 \mathrm{~m} / \mathrm{s}$ (Klymak et al., 2006). ISWs can cause strong shear flow in seawater during its spreading(Osborne and Burch, 1980), and exert strong shearing force as well as a large lateral deviation to a riser in a sudden time, which may eventually unexpectedly destroy the entire pipe system(Guo et al., 2013). ISWs occur frequently and are difficult to predict them in time, so there is a strong possibility that a drilling riser suffers impacts from ISWs during installation/relocation or evacuation in harsh environments. Particularly, such an ISW impact is more serious on a hang-off riser than a normal connected riser.

Some scholars studied the loads on structures exerted by internal waves. Cai et al.(Cai et al., 2003, 2006, 2008; Xie et al., 2010, 2011) adopted Morison's empirical formula and a modal separation method to estimate the forces and torques exerted by internal solitons on cylindrical piles. Zha et al.(2012) estimated the force and torque exerted by ocean internal waves on a submerged vertical cylindrical pile by using nautical X-band radar observations and in-situ buoyancy frequency data. Song et al.(2011) compared the actions by surface waves and ISWs on a Spar platform with a mooring system. Si et al.(2012) studied the shearing forces and torques by large-amplitude ISWs on a supposed rigid pile in the South China Sea. Guo et al.(2013) researched the dynamic responses of a top tensioned riser under combined ISW excitation, surface wave and vessel motion. Deng et al.(2015) proposed a quasi-static procedure to evaluate the impact of ISWs on a connected drilling riser under combined loads of ocean currents, surface waves and ISWs.

In previous research, various authors introduced solution methods, assistant software and response characteristics of hang-off riser dynamics. However, influences, such as damping forces and vessel motion, in the existing methods were normally neglected, and there is room to improve the numerical procedures. As for ISWs, most existing articles focused on their generation and distribution as well as the wave characteristics. Some articles discussed the impact of ISWs on fictitious cylindrical piles; however, few papers have reported the influence of ISWs on top tensioned drilling risers in detail. More importantly, few reports have evaluated the impact of ISWs on hangoff drilling risers.

In this paper, a time-domain dynamic FEM method is established by the Wilson- $\theta$ algorithm for a hang-off drilling riser, and dynamic envelopes of the hang-off riser properties are compared in different situations. Innovations in this paper are reflected in the following two aspects: in the hang-off dynamic procedures, the preconditioned GMRES is adopted to solve the large, sparse non-symmetric linear system; and the combined excitation of a non-uniform current, surface wave, ISW and vessel motion are considered in hang-off riser dynamics for the first time. Moreover, a dynamic envelope analysis of hang-off risers is visualized to reveal the extreme properties rather than the detailed dynamic variations over time, and this method is more convenient for drilling riser design and hang-off riser operation.

\section{Riser model and calculation equations}

\subsection{Riser model and governing equation}

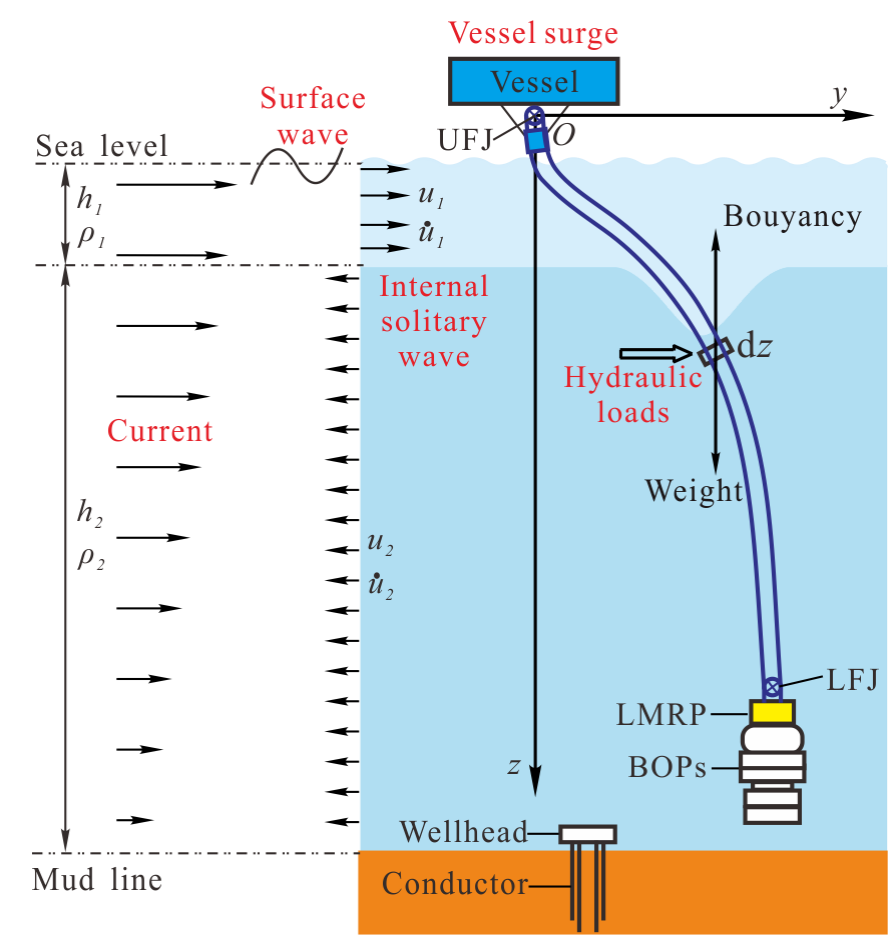

Fig. 1. Sketch of a hang-off drilling riser model

Fig. 1 displays a riser model in hang-off mode. The bottom end of the riser has no constraints, but may connect with a mass block (LMRP/BOPs); the top end of the riser is supported on tensioners (soft hang-off) or from a gimbal spider at the drill floor (hard hangoff), and moves with the motion of a floating vessel. In this paper, vessel heaving and riser vertical vibrations are neglected, while the in-line deformation and riser stress are the main considerations. 
The riser body is assumed to be a homogeneous, isotropic and linear elastic steel tube with a constant cross-section; seawater fills the entire pipe annulus, with zero flow velocity in the riser, and the entire riser body is deemed to be fully immersed in seawater.

Considering the effective axial force, damping force, and combined hydraulic loads, the forth order partial differential equation of a plane Euler-Bernoulli beam-column model is applied as the following riser governing equation:

日 $\frac{\partial^{4} y}{\partial z^{4}}+m \frac{\partial^{2} y}{\partial t^{2}}-T_{e}(z) \frac{\partial^{2} y}{\partial z^{2}}-\frac{\partial T_{e}(z)}{\partial z} \frac{\partial y}{\partial z}+c \frac{\partial y}{\partial t}=f(z, t)$

where, $z$ is the vertical coordinate of the riser system, which begins from UFJ with a positive direction that is the same as gravity, $\mathrm{m} ; y$ or $y(z, t)$ is the in-line lateral deviation of the riser, $\mathrm{m}$; $t$ is time, $\mathrm{s}$; $E$ is Young's modulus, $\mathrm{Pa} ; I$ is the rotational inertia of the riser cross-section, $\mathrm{m}^{4} ; c$ is the damping coefficient, $\mathrm{kg} /(\mathrm{m} \cdot \mathrm{s}) ; m$ is the total mass per unit riser length, including the riser body, accessory pipelines and contained fluid, $\mathrm{kg} / \mathrm{m} ; T_{e}(z)$ is the effective axial force of the riser cross-section, $\mathrm{N}$; and $f(z, t)$ is the hydraulic loads per unit riser length, $\mathrm{N} / \mathrm{m}$

For a hang-off drilling riser, $T_{e}(z)$ is calculated by:

$$
T_{e}(z)=W+\left[W-\left(\rho_{w} A_{o}-\rho_{f} A_{i}\right) g\right] \cdot\left(L_{r}-z\right)
$$

where, $W_{b}$ is the suspending weight at riser bottom, i.e., the weight of LMRP and BOPs, $\mathrm{N} ; W_{e}$ is the submerged weight of the entire riser cross-section per unit length, $\mathrm{N} / \mathrm{m} ; L_{r}$ is the total riser length, $\mathrm{m} ; \rho_{\mathrm{w}}$ and $\rho_{f}$ are the density of the seawater and contained fluid in the riser, $\mathrm{kg} / \mathrm{m}^{3}$; and $A_{r}$ and $A_{i}$ are the areas of the outer and inner riser cross-sections, respectively, $\mathrm{m}^{2}$.

The bottom end of a hang-off riser is free, and its top end is commonly simplified as a hinge constraint. Hence, the boundary conditions are:

$$
\left\{\begin{aligned}
\left.y(z, t)\right|_{z=0}=S(t), & \left.\frac{\partial^{2} y}{\partial z^{2}}\right|_{z=0}=\frac{K_{u}}{\theta} \frac{\partial y(0, t)}{\partial z} ; \\
\left.\frac{\partial y}{\partial z}\right|_{z=L_{r}}=0, & \left.\frac{\partial^{3} y}{\partial z^{3}}\right|_{z=L_{r}}=0 .
\end{aligned}\right.
$$

where, $\boldsymbol{S}(t)$ represents the horizontal deviation of vessel motion to its initial location, $\mathrm{m} ; K_{u}$ is the rotation stiffness of UFJ, $\mathrm{N} \cdot \mathrm{m} / \mathrm{rad}$.

In this paper, vessel surge is the main motion of a floating vessel, and is assumed to have the same direction of the riser in-line deviation. In hang-off dynamic analysis, the original point of $y$ is the location of UFJ after the initial offset of the vessel. Therefore, the inline deviation of UFJ (vessel surge) $\boldsymbol{S}(t)$ can be expressed from Sexton and Agbezuge(1976) and is the sum of the vessel drift and instantaneous response of the vessel to random waves.

\subsection{Hydraulic excitation loads}

To consider extreme situations, the lateral direction of all hydraulic loads, motion of vessel surge and in-line movement of the riser are assumed to be in the same 2-D plane ( yoz ). The modified Morison's Equation(Morison et al., 1950; Sexton and Agbezuge, 1976) is normally used to calculate the lateral hydraulic loads per unit riser length, i.e., $f(z, t)$ :

$$
\begin{aligned}
f(z, t)= & \frac{\pi \rho_{w} D_{e}^{2}}{4}\left[C_{M} \dot{\mu}-\left(C_{M}-1\right) \frac{\partial^{2} y}{\partial t^{2}}\right] \\
& +\frac{\rho_{w} D_{e} C_{D}}{2}\left|u-\frac{\partial y}{\partial t}\right|\left(u-\frac{\partial y}{\partial t}\right)
\end{aligned}
$$

where, $C_{M}$ is the inertia coefficient, dimensionless; $C_{D}$ is the drag coefficient, dimensionless; $D_{e}$ is the hydraulic diameter of the drilling riser (commonly equivalent to the maximal outer diameter of the riser plus its auxiliary lines), $\mathrm{m} ; u$ and $\dot{u}$ are the total water velocity $(\mathrm{m} / \mathrm{s})$ and acceleration $\left(\mathrm{m} / \mathrm{s}^{2}\right)$ in the horizontal direction $y$; and $\frac{\partial y}{\partial t}$ and $\frac{\partial^{2} y}{\partial t^{2}}$ are the horizontal velocity and acceleration of the riser structure, respectively. The velocity of the ocean currents $u_{c}(z)$ can be acquired from a known current profile, and the velocity $u_{w}(z, t)$ and acceleration $\dot{u}_{w}(z, t)$ of the surface wave can be calculated from a regular wave (e.g., Airy' linear wave theory) or random wave (e.g., Pierson-Moskowitz spectrum theory).

Through linearization, the absolute value in Eq. (4) can be replaced by $\eta(z, t)$ as follows:

$$
\eta(z, t)=\left|u-\frac{\partial y}{\partial t}\right|=\frac{8}{3 \pi}\left(u-\frac{\partial y}{\partial t}\right)_{0}
$$

where, $\left(u-\frac{\partial y}{\partial t}\right)_{0}$ is the amplitude of $\left(u-\frac{\partial y}{\partial t}\right), \mathrm{m} / \mathrm{s}$. Set $K_{M}=\frac{\pi \rho_{w} D_{e}^{2}}{4} C_{M}, K_{D}=\frac{\rho_{w} D_{e} C_{D}}{2}$, and $m_{a}=\frac{\pi \rho_{w} D_{e}^{2}}{4}\left(C_{M}-1\right) ; m_{a}$ is the added mass of the entrained water, $\mathrm{kg} / \mathrm{m}$. Correspondingly, the governing equation Eq. (1) can be converted to a new form, as follows:

$$
\begin{aligned}
& \boxminus \frac{\partial^{4} y}{\partial z^{4}}+\left(m+m_{a}\right) \frac{\partial^{2} y}{\partial t^{2}}-T_{e}(z) \frac{\partial^{2} y}{\partial z^{2}}-\frac{\partial T_{e}(z)}{\partial z} \frac{\partial y}{\partial z} \\
& +\left(c+K_{D} \eta\right) \frac{\partial y}{\partial t}=K_{D} \eta u+K_{\mu} \dot{\mu}
\end{aligned}
$$

\subsection{ISW Simulation}

Generally, pycnocline or thermocline are a requirement to form ISWs. In a sea area with pycnocline, seawater has a density difference along a vertical distribution. This could be simplified as a two-layer model with two different densities if the tiny pycnocline layers are neglected. In this paper, the two-layer model(Osborne and Burch, 1980; Song et al., 2011) is applied to simulate ISWs. Supposing that $h_{1}, \rho_{1}, h_{2}$ and $\rho_{2}$ are the depth thickness (m) and water density $\left(\mathrm{kg} / \mathrm{m}^{3}\right)$ of the upper and the lower seawater layer, respectively; the total water depth is $d$, and $d=h_{1}+h_{2} . \eta_{0}$ is the amplitude of ISW, $\mathrm{m}$; if $h_{1}<h_{2}, \eta_{0}$ is negative, the wave is a down-concave type; while if $h_{1}>h_{2}, \eta_{0}$ is positive, the wave is an up-convex type.

The KdV equation and the modified $\mathrm{KdV}$ equation are two main models for simulating ISWs, but the KdV equation gives a better solution when the ISW has a smaller amplitude $\left(\eta_{0} / d<0.1\right)$. Therefore, the $\mathrm{KdV}$ equation is applied in this paper. In the $\mathrm{KdV}$ model(Osborne and Burch, 1980; Song et al., 2011; Guo et al., 2013), 
the ISW interface $\eta(t)$, horizontal velocities $u_{s}(t)$ and horizontal accelerations $\dot{u}_{s}(z, t)$ of the upper and lower seawaters layer are, in order:

$$
\eta(t)=\eta_{0} \operatorname{sech}^{2} \phi
$$

$u_{s}(t)=\left\{\begin{array}{l}\frac{c \eta_{0}}{h_{1}} \cdot \operatorname{sech}^{2} \phi, \text { i n upper I ayer } \\ -\frac{c \eta_{0}}{h_{2}} \cdot \operatorname{sech}^{2} \phi, \text { i n I ower I ayer }\end{array}\right.$

$\dot{u}_{s}(z, t)=\left\{\begin{array}{l}\frac{2 c \eta_{0} C_{p} \cdot z}{h_{1} l} \cdot \operatorname{sech}^{2} \phi \mathrm{t} \text { anh } \phi, \text { i n upper I ayer } \\ -\frac{2 c \eta_{0} C_{p}(d-z)}{h_{2} l} \cdot \operatorname{sech}^{2} \phi \mathrm{t} \text { anh } \phi, \text { i n I over I ayer }\end{array}\right.$

where, $\phi=\frac{y-C_{p} t}{l}$ is the phase angle of ISW, rad; $C_{p} \approx c\left[1+\frac{\eta_{0}\left(h_{2}-h_{1}\right)}{2 h_{1} h_{2}}\right], \quad c=\left[\frac{g \Delta \rho h_{1} h_{2}}{\bar{\rho}\left(h_{1}+h_{2}\right)}\right]^{0.5}, \Delta \rho=\rho_{2}-\rho_{1}$, $\left.\bar{\rho}=0.5 \rho_{2}+\rho_{1}\right) ; l=\frac{\lambda}{2} \approx \frac{2 h_{1} h_{2}}{\sqrt{3 \eta_{0}\left|h_{2}-h_{1}\right|}}, \lambda$ is the wave length, $\mathrm{m} ; z$ is the depth to the sea level, $\mathrm{m}$; and $y$ is the initial in-line displacement in the horizontal direction according to the original point, $\mathrm{m}$.

Considering the most extreme situation, i.e., neglecting all angles between different water movements in horizontal direction, the total water velocity and acceleration are:

$$
\left\{\begin{array}{l}
u(z, t)=u_{c}(z)+u_{w}(z, t)+u_{s}(t) \\
\dot{u}(z, t)=\dot{u}_{w}(z, t)+\dot{u}_{s}(z, t)
\end{array}\right.
$$

\subsection{Von Mises Effective Stress}

The Von Mises stress failure criterion is one of the main design criteria in API RP 16Q(2001), and it is computed by:

$\sigma_{v m}=\frac{1}{\sqrt{2}} \cdot \sqrt{\left(\sigma_{r}-\sigma_{\theta}\right)^{2}+\left(\sigma_{r}-\sigma_{z}\right)^{2}+\left(\sigma_{\theta}-\sigma_{z}\right)^{2}}<\frac{2}{3} \sigma_{s}$

where, $\sigma_{v m}$ is the Von Mises stress of a riser body, $\mathrm{Pa}, \sigma_{s}$ is the yield stress of riser material, $\mathrm{Pa} ; \sigma_{r}, \sigma_{\theta}$, and $\sigma_{z}$ are the three principal stresses, Pa: radial stress, hoop stress and axial compound stress, respectively.

Radial stress and hoop stress can be acquired by Lamé's Formula(Lee, 1998). Axial compound stress $\sigma_{z}$ at the convex side of the riser is the sum of the axial effective stress $\sigma_{T_{e}}$ and bending tensile stress $\sigma_{M}$, i.e.:

$\sigma_{z}=\sigma_{T_{e}}+\sigma_{M}=\frac{T e}{A_{o}-A_{i}}+\frac{M}{I_{r}} \cdot R_{r}$

\section{Numerical solution methods}

\subsection{Governing equation discretization by FEM}

The weighted residual method is applied to conduct finite element discretization. Considering a two-dimensional plane beam element, each element has four degrees of freedom (DOFs), $\delta^{e}=\left[\begin{array}{llll}v_{i}, & \theta_{i}, & v_{j}, & \theta_{j}\end{array}\right]^{T}$. The shape function matrix is $\mathbf{N}=\left[\begin{array}{llll}N_{1} & N_{2} & N_{3} & N_{4}\end{array}\right]$, and the element length is $/$. Therefore, $y=\mathbf{N} \cdot \delta^{e}$. Where,

$\left\{\begin{array}{l}N_{1}=1-3 \frac{z^{2}}{l^{2}}+2 \frac{z^{3}}{l^{3}} \\ N_{2}=z-2 \frac{z^{2}}{l}+\frac{z^{3}}{l^{2}} \\ N_{3}=3 \frac{z^{2}}{l^{2}}-2 \frac{z^{3}}{l^{3}} \\ N_{4}=-\frac{z^{2}}{l}+\frac{z^{3}}{l^{2}}\end{array}\right.$

Based on Eq. (7) and applying the Galerkin method, the stiffness matrix $\mathbf{K}^{e}$, mass matrix $\mathbf{M}$, damping matrix $\mathbf{C}^{\mathbf{e}}$, and equivalent nodal force vector $F^{e}$ for each element can be acquired :

$$
\left\{\begin{array}{l}
\mathbf{K}=\int_{0}^{l} \mathbf{N}^{T} \theta \mathbf{N}^{\prime} d z+\int_{0}^{l} \mathbf{N}^{T} T_{e}(z) \mathbf{N d} z \\
\mathbf{M}=\int_{0}^{l} \mathbf{N}\left(m+m_{a}\right) \mathbf{N d} z \\
\mathbf{C}=\int_{0}^{l} \mathbf{N}\left(c+K_{D} \eta\right) \mathbf{N d} z \\
\mathbf{F}^{e}=\int_{0}^{l}\left(K_{D} \eta u+K_{d} \dot{\mu}\right) \mathbf{N} d z
\end{array}\right.
$$

After assembling these elemental matrices into system matrices in global coordinates, the final FEM equation of the riser system is:

$\mathbf{M} \ddot{\mathbf{S}}_{t}+\mathbf{C} \dot{\delta}_{t}+\mathbf{K} \delta_{t}=\mathbf{F}_{t}$

where, $\mathbf{M}, \mathbf{C}$, and $\mathbf{K}$ are the mass matrix, damping matrix and stiffness matrix of the riser system, respectively; $\ddot{\delta}, \dot{\delta}$, and $\delta$ are the vectors of acceleration, velocity and displacement of each DOF, respectively; and $\mathbf{F}_{t}$ is the vector of time-dependent hydrodynamic loads.

\subsection{Time-domain dynamic calculation by the Wilson- $\theta$ method}

Newmark- $\beta$ and Wilson- $\theta$ are two commonly used methods for time-domain dynamic analysis. Because Wilson- $\theta$ can effectively restrain accumulation errors over a relatively long time, it is chosen to simulate the dynamic excitation under combined ocean currents, surface waves, ISWs and vessel motion. The specific algorithm steps are narrated as follows:

(1) Preliminary calculation

(1) Calculate the system matrixes $\mathbf{M}, \mathbf{C}$, and $\mathbf{K}$;

(2) Based on the initial conditions $\delta_{0}$ and $\dot{\delta}_{0}$, calculate $\ddot{\delta}_{0}=\mathbf{M}^{-1}\left(\mathbf{F}_{\mathbf{0}}-\mathbf{C} \dot{\delta}_{0}-\mathbf{K} \delta_{0}\right)$

(3) Choose a proper time step $\Delta t$, set $\theta=1.4$, and calculate the interim parameters:

$$
\begin{aligned}
& a_{1}=\frac{6}{\theta^{2} \Delta t^{2}}, \quad a_{2}=\frac{3}{\theta \Delta t}, \quad a_{3}=\frac{\theta \Delta t}{2}, \quad a_{4}=\frac{6}{\theta^{3} \Delta t^{2}}, \\
& a_{5}=-\frac{6}{\theta^{2} \Delta t}, \quad a_{6}=\left(1-\frac{3}{\theta}\right), \quad a_{7}=\frac{\Delta t}{2}, \quad a_{8}=\frac{\Delta t^{2}}{6} \text {. }
\end{aligned}
$$

(4) Calculate the effective stiffness matrix $\tilde{\mathbf{K}}: \tilde{\mathbf{K}}=\mathbf{K}+\mathbf{a}_{1} \mathbf{M}+\mathbf{a}_{2} \mathbf{C}$, and apply the boundary conditions.

(2) For each time step: 
(1) Calculate the vector of the equivalent nodal force at time $t+\theta \Delta t: \mathbf{F}_{t+\theta \Delta t}=\mathbf{F}_{t}+(\theta-1) \cdot\left(\mathbf{F}_{t+\Delta t}-\mathbf{F}_{t}\right) ;$

(2) Calculate the vector of the effective equivalent nodal force, and then, apply the boundary conditions:

$\left.\left.\tilde{\mathbf{F}}_{t+\theta \Delta t}=\mathbf{F}_{t+\theta \Delta t}+\mathbf{M} \mathbf{a}_{1} \delta_{t}+2 \mathbf{a}_{2} \dot{\delta}_{t}+2 \ddot{\delta}_{t}\right)+\mathbf{G} a_{2} \delta_{t}+2 \dot{\delta}_{t}+a_{3} \ddot{\delta}_{t}\right)$

(3) Solve the linear systems and acquire the displacement $\delta_{t+\theta \Delta t}$ : $\tilde{\mathbf{K}} \delta_{t+\theta \Delta t}=\tilde{\mathbf{F}}_{t+\theta \Delta t} ;$

(4) Calculate the parameters at the next time step $t+\Delta t$ :

$\ddot{\delta}_{t+\Delta t}=a_{4}\left(\delta_{t+\theta \Delta t}-\delta_{t}\right)+a_{5} \dot{\delta}_{t}+a_{6} \ddot{\delta}_{t}$

$\dot{\delta}_{t+\Delta t}=\dot{\delta}_{t}+a_{1}\left(\ddot{\delta}_{t+\Delta t}+\ddot{\delta}_{t}\right)$

$\delta_{t+\Delta t}=\delta_{t}+\Delta t \dot{\delta}_{t}+a_{8}\left(\ddot{\delta}_{t+\Delta t}+2 \ddot{\delta}_{t}\right)$

(5) Calculate the final parameters of each node at time $t+\Delta t$, including the horizontal displacement $y$, bending moment $M$, shearing force $Q$, and Von Mises stress $\sigma_{v m}$.

The linear system for each time step $\left(\tilde{\mathbf{K}} \delta_{t+\theta \Delta t}=\tilde{\mathbf{F}}_{t+\theta \Delta t}\right)$ is a large, sparse non-symmetric linear system. Some traditional numerical methods, such as the LU-decomposition method (where 'LU' stands for 'lower upper') and the Gauss-Seidel iterative method, can neither acquire relatively accurate results nor resolve such a large system efficiently in time. Therefore, a new method should be considered.

The preconditioned GMRES algorithm(Saad and Schultz, 1986) is an effective iterative method for numerically solving of a nonsymmetric linear system, and it has been successfully used to solve some large sparse equations in engineering problems(Pu et al., 2014; Zhao et al., 2015). In this paper, the GMRES is applied to conduct the Wilson- $\theta$ process, and the preconditioner is calculated by an incomplete LU-decomposition method. The specific GMRES algorithm can be cited from Mittal and Al-Kurdl(2003).

\subsection{Calculation process and program verification}

The entire dynamic FEM process in this paper is realized by a selfdeveloped MATLAB program, and Fig. 2 shows the flow chart of the analysis.

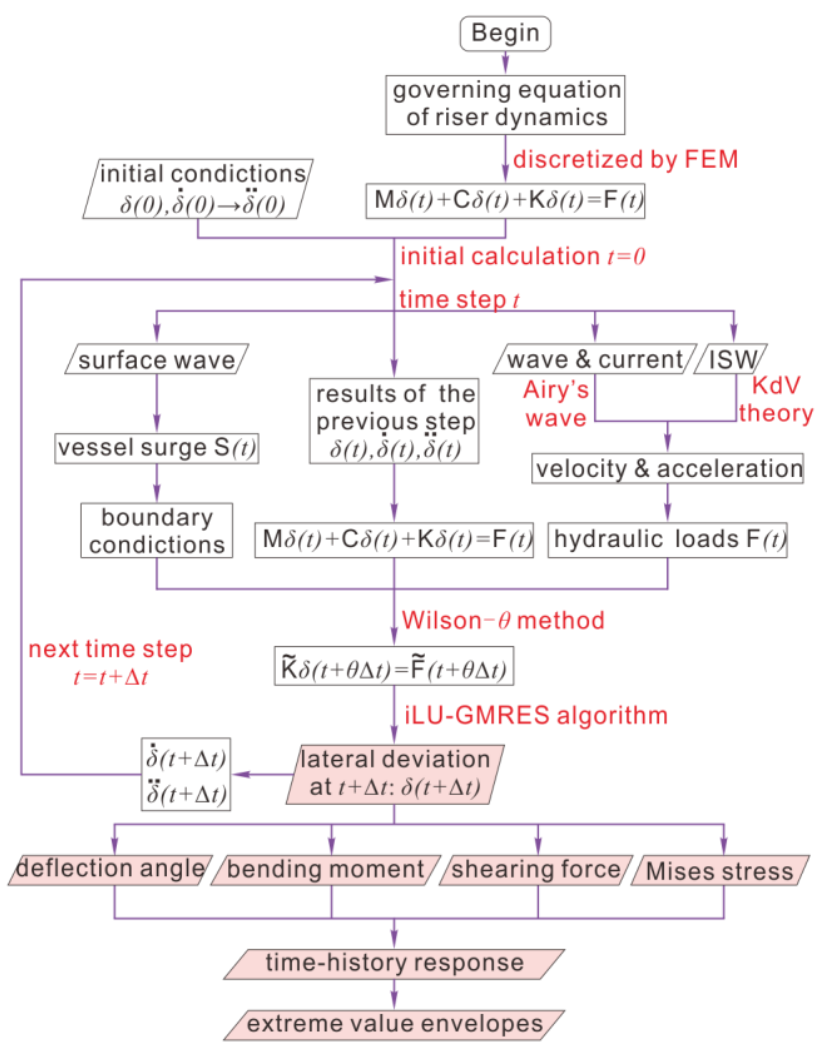

Fig. 2. Flow chart of the riser dynamic analysis at each time step

In the entire procedure, three key steps should be emphasized: The first point is the simulation of ISW to find the hydraulic loads. In the current paper, KdV theory is selected to compute the field of the ISW velocity and acceleration according to the water depth, ISW amplitude and ISW type. In fact, there are several ISW calculation models, such as KdV, mKdV, eKdV and MCC(Xie et al., 2009); hence, careful judgement is needed to choose a proper ISW theory in other applications. The second point is the realization of the Wilson- $\theta$ method and iLU-GMRES algorithm. The two algorithms determine the accuracy and efficiency of the entire time-domain FEM process and require several loops during MATLAB realization. The third point is the post-processing, including the calculation of the bending moment, shearing force, Von Mises stress, and finally, the envelopes.

It is indispensable to perform a strict verification for the selfdeveloped MATLAB program, and comparing the simulation results with field test data is generally the most reliable choice. However, because of the complexity and unpredictability of ISW, to date, there are no credible sea test data and no available experimental data of the coupled impact of vessel motion and ISW to a hang-off riser in current searchable references. Hence, the next best method is used herein, i.e., separately comparing the result of the ISW flow field and the results of the hang-off riser dynamics by our MATLAB program with the published results, as shown in Fig. 3.

(1) Fig. 3-a provides the experimental data (dash line) and observed data (scattered points) of the force exerted by ISW(Lü et al., 2016); the solid line is the result of the proposed program in which the same parameters of the pipe and ISW are applied as the reference data. The maximal value $(-22.7 \mathrm{kN})$ and main trend are nearly the same from the three lines.

(2) Fig. 3-b shows the compared curves of the Von Mises stress envelope of a hard hang-off riser, in which $\mathrm{Wu}(\mathrm{Wu}$ et al., 2014) calculated the dash lines and the solid lines were acquired by the 
program with the same riser and water parameters. The main trends are also nearly the same; yet, some small differences exist because of the different simplification of the riser buoyancy between the research by $\mathrm{Wu}$ and this verification process.

Therefore, the capacity to simulate the ISW and hang-off riser dynamics can be determined by the self-developed MATLAB program to a certain level.

\section{Case calculation and discussion}

\subsection{Case data and preliminary calculation}

To begin, some abbreviated forms are defined in Table 1; these abbreviations are not commonly used in the literatures, but are only convenient for displaying in figures. In the following discussion, "riser properties" is a generic term of the in-line deviation, bending moment, shearing force and Von Mises stress of a hang-off riser; the "envelope" of any parameter means the scope between its minimal value and maximal value at each depth during the whole time and, accordingly, contains the most serious/extreme situation.

Table 1. Explanation of the abbreviations in the figures

\begin{aligned} & \hline Short form Full form \\ & \hline OC Ocean current \\ & SW Surface wave \\ & IW Internal solitary wave/ISW \\ & VS Vessel surge \\ & Soft/Hard Soft hang-off mode/Hard hang-off mode \\ & IW amp/drift amp Amplitude of ISW/Amplitude of vessel drift \\ & Den Density ratio of the two seawater layers \\ & TS Towing speed of floating vessel \\ & $\mathrm{R}$ Drilling riser \\ & \hline\end{aligned}

Normally, drilling risers have different wall thicknesses and hydraulic diameters along their entire depth. Various mechanic parameters, such as the shearing force and Mises stress, are discontinuous or always change sharply at the connection points between different riser sizes. To avoid confusion between these sudden changes by size alterations and sudden impacts by ISWs, this case applies a uniform riser diameter along its whole length. Table 2 lists the main case data.

Table 2. Case data

\begin{aligned} \hline Parameter & Value \\ \hline Riser length & $1078(\mathrm{~m}) \\$ Outer \& inner diameter of riser & $0.5334 \& 0.48895(\mathrm{~m}) \\$ Hydraulic diameter of riser & $1.1938(\mathrm{~m}) \\$ Length of riser joint & $22.86(\mathrm{~m}) \\$ Weight per riser joint in air & $165352.4(\mathrm{~N}) \\$ Weight per riser joint in seawater & $15663.1(\mathrm{~N}) \\$ Young's Elasticity module of riser steel & $2.06 \times 10^{11}(\mathrm{~Pa}) \\$ Weight of LMRP in seawater & $1.1 \times 10^{6}(\mathrm{~N}) \\$ Weight of BOP in seawater & $2.2 \times 10^{6}(\mathrm{~N}) \\$ Depth of the upper \& lower seawater layer & $230 \& 863(\mathrm{~m}) \\$ Density of the upper \& lower seawater layer & $1023 \& 1028\left(\mathrm{~kg} / \mathrm{m}^{3}\right) \\$ Tide-driven \& wind-driven current velocity & $0.5 \& 0.5(\mathrm{~m} / \mathrm{s})\end{aligned}$

SW height \& SW period $8.0(\mathrm{~m}) \& 10(\mathrm{~s})$

IW amplitude $-70(\mathrm{~m})$

Single amplitude \& period of vessel drift 8.0 (m) \& 200 (s)

Drag coefficient $\&$ inertia coefficient $1.0 \& 2.0$

Damping coefficient $0.03(\mathrm{~kg} /(\mathrm{m} \cdot \mathrm{s}))$

Element length \& time step $2.286(\mathrm{~m}) \& 2.0(\mathrm{~s})$

Fig. 4 displays the calculation results of three preliminary parameters. In a flow field excited by ISW, the velocity (Fig. 4-a) changes steadily during ISW spreading, but maintains a constant value in each seawater layer; whereas the acceleration in the ISW flow field not only changes with time, but is also different at each water depth. The response curve of vessel surge is shown in Fig. 4-b, in which a random wave is simulated by the Pierson-Moskowitz (P-M) spectrum. UFJ is connected to the drill vessel, so Fig. 4-b also represents the deviation response of the riser top. Fig. 4-c shows the envelope of combined hydraulic loads $(\mathrm{OC}+\mathrm{SW}+\mathrm{IW})$. Since the addition of ISW, the hydraulic loads distribution has a larger change around $180 \mathrm{~m}$ under sea level; ISWs can increase the hydraulic loads largely in the upper layer, yet decrease or negatively increase hydraulic loads in the lower layer at some times during ISW propagating.

\subsection{Case discussion}

Fig. 5 shows the results of riser responses under combined $\mathrm{OC}+\mathrm{SW}+\mathrm{IW}+\mathrm{VS}$ loads. The bottom of the riser connects with a LMRP, and the top is in soft hang-off mode. This is the main situation in the following discussion. To verify the program further, the dynamic results at four time points, as determined by MATLAB, are compared with the results from the ABAQUS and DeepRiser software. From the contrast curves, the main trends match very well with the results of the proposed program and two types of commercial software. The small departures come from the differences between the real dynamics and quasi-dynamic process. Such comparisons further demonstrate the reliability of the model and program.

Moreover, it is very difficult to load a complicated load directly in FEM software (ABAQUS, ANSYS, etc.) or special riser software (DeepRiser, FlexCom, OrcaFlex, etc.), e.g., the coupled dynamic effects of the ISW field and vessel surge in this paper. However, in MATLAB program, nonlinear profiles of ISW velocity and acceleration can be loaded freely in the dynamic program, as well as the dynamic boundary condition of vessel surge. Therefore, the MATLAB program displays both good reliability and flexibility, and can be used for complex riser dynamic analysis or can act as a good reference for adjusting special riser software.

In this envelope by MATLAB, the time range of the ISW influence is between $1000 \mathrm{~s}$ and $3000 \mathrm{~s}$, and the peak value is between $1500 \mathrm{~s}$ and $2500 \mathrm{~s}$. The maximal Von Mises stress is $71 \mathrm{MPa}$ at $60 \mathrm{~m}$ under sea level. Fig. 6 displays the envelopes of the riser properties under different loads, in which the riser top is in soft hang-off mode and a LMRP is suspended at the riser bottom. In Fig. 6-a, by the single effect of ISW, the in-line deviation range of riser bottom is $-29 \mathrm{~m} \sim$ $29 \mathrm{~m}$. Vessel surge also increases the range of riser deformation and stress, and creates two stress swells (two sections respectively near the top and the bottom of the riser). The amplitude of the in-line 
deviation along the entire depth increased by vessel surge is close to the amplitude of the vessel surge at the sea level. Under the combined loads of $\mathrm{OC}+\mathrm{SW}+\mathrm{VS}+\mathrm{IW}$, the range increase to $-25 \mathrm{~m} \sim 50 \mathrm{~m}$. In Fig. 6-b and Fig. 6-d, the bending moment envelope and Misses stress envelope clearly increase over the entire depth- and the increases are particularly dramatic in the upper layers. In Fig. 6-c, the shearing force has a large positive increase near sea level and has a "peak state" increase near the ISW interface.

Fig. 7 shows the envelopes of riser properties with different hangoff modes, in which the riser bears combined loads $(\mathrm{OC}+\mathrm{SW}+\mathrm{IW}+\mathrm{VS})$. In hard hang-off mode, the riser has a very large response in the upper section and the depth range is between $0 \mathrm{~m} \sim$ $150 \mathrm{~m}$. In addition, the suspending weight (LMRP and BOP) can increase the axial tension and effectively restrain bending deformation and horizontal deviation. Thus, the riser connected with a LMRP and BOP has the smallest envelopes in regard to the in-line deviation, bending moment and shearing force, while the riser without any other suspending weight (riser only) has the largest envelopes of these parameters.

Fig. 8 shows the influences of different ISW parameters on the riser properties. Shearing force (Fig. 8-a) and bottom riser displacement (Fig. 8-b) have larger envelopes if the ISW amplitude (absolute value) increases. In addition, if ISW has an opposite amplitude (negative value $\rightarrow$ positive value), the ISW type will change (concave type $\rightarrow$ convex type), as will the depth range affected by the ISW. What's more, if seawater has a larger density difference between the upper and lower layers, deformation and stress of the riser will have larger envelopes (Fig. 8-c and Fig. 8-d).

Fig. 9 shows the influences of different vessel parameters on the riser properties. The in-line deviation envelope of the entire riser enlarges with the increase of the vessel drift amplitude (Fig. 9-a), but the influence on the Mises stress by the change of the drift amplitude is not apparent (Fig. 9-b). The towing speed of a floating vessel after initial acceleration is approximately equivalent to an added current velocity along the entire riser length. In Fig. 9-c and Fig. 9-d, a positive towing speed (e.g., $+2 \mathrm{~m} / \mathrm{s}$ ) with the same direction as the wave-current velocity can counteract the relative velocity between the riser and seawater. Thus, it can reduce the hydraulic drag force and decrease the shearing force and Mises stress. However, if the positive towing speed is too large (e.g., $+4 \mathrm{~m} / \mathrm{s}$ ) or the towing speed is negative (e.g., $-2 \mathrm{~m} / \mathrm{s}$ ), the relative velocity and the drag force will increase, accordingly, the riser will have a larger deformation and larger mechanical parameters.

\subsection{Uncertainties and other factors}

Since the coupling of ISW and vessel surge for a hang-off riser is a new topic and is very complicated, two potential uncertainties exist in the global dynamic procedure such that: a 2-D method in an extreme situation, i.e., all of the angles between different hydraulic loads are neglected. However, in real situations, the direction of the hydraulic loads is random and a 3-D model is necessary in further research. The other uncertainty is that the axial movement of the riser is not considered. However, the axial heaving of a riser is apparent in soft hang-off mode, and has a large influence on the clearance between the riser bottom and other subsea equipment. Thus, in future analyses, a coupled procedure with both lateral movement and axial heaving will be meaningful for determining the optimal hang-off operation. Anyhow, the major purpose of this paper is to establish a dynamic procedure and develop a related program, to reveal the influence of ISW and vessel motion on a hang-off drilling riser. Therefore, such simplifications are necessary and the algorithm is competent.

The current discussion uses a coupled model, in which the ocean current, surface wave, ISW and vessel surge are considered, so there are too many factors (including environmental conditions and operation parameters) that influence the lateral dynamic behaviour of the riser, such as the water depth, direction and velocity of ocean current, amplitude and period of surface wave, parameters of the vessel motion, pipe size and material properties, buoyancy module distribution, and rotational stiffness of UFJ. Previous research has discussed these factors for marine risers in detail and are beneficial for engineering applications, such as the work by Sexton and Agbezuge(1976), and Moghiseh et al.(2012). Hence, such analyses will not be repeated but new considerations of ISWs on a hang-off riser bearing combined $\mathrm{OC}+\mathrm{SW}+\mathrm{IW}+\mathrm{VS}$ loads are examined.

Moreover, the damping coefficient is an indispensable factor for dynamic analysis. For marine risers, a proper damping coefficient comes from accurate experiments according to the size, shape and material of the pipe body. A larger damping coefficient value could weaken the dynamic amplitude and decrease the response duration; a smaller value lead to the opposite effect. In the case data, the value of the damping coefficient is determined by the recommendation of API RP 16Q and some relevant literatures for risers with an outer diameter of $0.5334 \mathrm{~m}$. So do the selection of drag coefficient and inertia coefficient in Table 2.

\subsection{Possible engineering considerations}

Compared with the connected mode, drilling risers in hang-off mode lose the constraint at the riser bottom and accordingly lose the effect of excess top tension. Therefore, a disconnected riser system becomes more flexible than a connected riser, and has larger envelope of lateral deformation and bears larger forces. This means that the hang-off mode is more dangerous and more fragile than the connected mode, especially in harsh ocean environment. Particularly, a hang-off riser without any other suspending weight is the most dangerous situation. Hence, retraining a LMRP at the bottom of a hang-off riser may be safer than a single riser string during vessel relocation and evacuation.

Floating vessel motion is an apparent factor that expands the envelopes of the riser properties. Thus, limiting vessel drift and random motion should not be neglected for hang-off risers. Moreover, during a vessel transfer or evacuation to a new location, maintaining a steady vessel towing speed is also effective for weakening the negative influence of unsteady vessel motion on a hang-off riser. And such a towing is better to be kept as a same direction of wave-current velocity and not exceed the maximal seawater velocity.

ISW can largely increase the deformation amplitude and stress envelope of a riser, particularly increasing the range of parameters in the upper seawater layers. Therefore, if an ISW occurs frequently in the working area, it is necessary to strengthen the riser section in the upper layer depth, for example, using slick joints in the upper layer depth and choosing riser joints with larger wall thickness.

In addition, ISW can largely increase the lateral deviation of the 
bottom of a hang-off riser. Therefore, in order to avoid terrible collisions between the bottom of a hang-off riser and other subsea equipment (especially when a LMRP and BOP suspended), it is highly needed to predict the deviation area of the riser bottom when the riser is under extreme combined loads $(\mathrm{OC}+\mathrm{SW}+\mathrm{IW}+\mathrm{VS})$. During vessel transfer or evacuation, it is very important to lift the riser system several meters and ensure that the riser bottom is far from the top of subsea equipment.

\section{Conclusions}

This paper establishes a dynamic FEM procedure for a hang-off drilling riser in which ISW and vessel motion are considered. In this procedure, the KdV theory is adopted to describe the ISW, and the Wilson- $\theta$ algorithm is used to realize the time-domain dynamic simulation process. Particularly, to improve the precision and efficiency of the numerical solution, the preconditioned GMRES algorithm is used for the first time to solve the large, sparse nonsymmetric linear system during each Wilson- $\theta$ time step. Furthermore, in this paper, envelope analysis of the riser deformation and mechanics is more visualized than dynamic time history analysis. Therefore, the dynamic calculation procedures and envelope analysis method will benefit optimal designing of hang-off risers and safe operation of platform relocation/evacuation.

Drilling risers are more dangerous in hang-off mode than in connected mode. That is because compared with the connected mode, the hang-off mode riser has a lower axial tension and a larger horizontal deformation; its bottom can dynamically deviate in a large space that may crash into other subsea equipment. ISW and vessel motion can largely increase such dangers in hang-off mode. Particularly, ISW can largely increase the envelopes of deformation parameters and mechanical properties of hang-off risers in the upper seawater layers and can dramatically increase the horizontal deviation of the bottom of hang-off risers.

Therefore, if ISW occurs frequently in the working area and the usual depth of the upper layer can be predicted, it is better to choose slick joints with a larger wall thickness in the upper layer depth. During real operation of transfer or evacuation, it is very important to lift the riser system several meters to avoid impact between the riser bottom and other subsea equipment. Moreover, to reduce the drag force of vessel motion on hang-off risers, it is advisable to limit vessel drift and random motion of floating vessels. During emergency evacuation, it is significant to optimize a steady towing speed, e.g., keeping a speed that has a similar direction as the wave-current direction, that should not exceed the maximal seawater velocity that the riser can bear.

\section{Acknowledgements}

This paper was supported by the "National Science Foundation of China"[Grant number: 51574261]; and the "National Basic Research Program of China(973 Program)"[Grant number: 2015CB251203].

\section{References}

Ambrose B.D., Grealish F., Whooley K., 2001. Soft hangoff method for drilling risers in ultra deepwater. OTC-13186-MS.

http://dx.doi.org/10.4043/13186-MS.
API RP 16Q, 2001. Recommended practice for design, selection, operation and maintenance of marine drilling riser systems. American Petroleum Institute.

Bybee K., 2002. Soft-hangoff method for drilling risers in ultradeep water. SPE-0202-0043-JPT. http://dx.doi.org/10.2118/02020043-JPT.

Cai S., Long X., Gan Z., 2003. A method to estimate the forces exerted by internal solitons on cylindrical piles. Ocean Engineering. 30(5): 673-689. http://dx.doi.org/10.1016/S00298018(02).

Cai S., Wang S., Long X., 2006. A simple estimation of the force exerted by internal solitons on cylindrical piles. Ocean Engineering. 33: 974-980. http://dx.doi.org/10.1016/j.oceaneng.2005.05.012.

Cai S., Long X., Wang S., 2008. Forces and torques exerted by internal solitons in shear flows on cylindrical piles. Applied Ocean Research. 30: 72-77. http://dx.doi.org/10.1016/j.apor.2008.03.001.

Chen W., Li M., Zheng Z., et al., 2015. Impacts of top-end vessel sway on vortex-induced vibration of the submarine riser for a floating platform in deep water. Ocean Engineering. 99: 1-8. http://dx.doi.org/10.1016/j.oceaneng.2015.03.002.

Dai W., Gao F., Bai Y., 2009. FEM analysis of deepwater drilling risers under the operability and hang-off working conditions. Journal of Marine Science and Application. 8: 156-162. http://dx.doi.org/10.1007/s11804-009-8114-0.

Deng S., Li C., Fan H., et al., 2015. Impact evaluation of internal solitary waves on a drilling riser. ISOPE-I-15-685.

Guo H., Zhang L., Li X., et al., 2013. Dynamic responses of top tensioned riser under combined excitation of internal solitary wave, surface wave and vessel motion. Journal of Ocean University of China(Oceanic and Coastal Sea Research). 12 (1): 6-12. http://dx.doi.org/10.1007/s11802-013-2079-y.

Head W., Power T.L., Royer B., 2013. Riser concepts for high motion vessels in ultradeep water. OTC-24229-MS. http://dx.doi.org/10.4043/24229-MS.

Iwona A.W., Lucyna B., Lukasz D., 2015. An analysis of dynamics of risers during vessel motion by means of the rigid finite element method. Ocean Engineering. 106: 102-114. http://dx.doi.org/10.1016/j.oceaneng.2015.06.053.

Klymak J.M., Pinkel R., Liu C.T., et al., 2006. Prototypical solitons in the South China Sea. Geophysical Research Letters. 33, L11607. http://dx.doi.org/10.1029/2006GL025932.

Lee J., 1998. Modified thin wall pipe formula for deep water application. ISOPE-I-98-113.

Magalhaes J.M., Silva da J.C.B., 2012. SAR observations of internal solitary waves generated at the Estremadura Promontory off the west Iberian coast. Deep Sea Research Part I: Oceanographic Research Papers. 69:12-24. http://dx.doi.org/10.1016/j.dsr.2012.06.002.

Mittal R.C., Al-Kurdi A.H., 2003. An efficient method for constructing an ILU preconditioner for solving large sparse nonsymmetric linear systems by the GMRES method. Computers \& Mathematics with Applications. 45(10-11): 17571772. http://dx.doi.org/10.1016/S0898-1221(03)00154-8.

Moghiseh A., Chaloshtory H. R., Rahi A., 2012. Effect of middle 
tension on dynamic behavior of marin risers. Journal of Maritime Research. 9(1): 63-70.

Morison J.R., O'Brien M.P., Johnson J.W., et al., 1950. The force exerted by surface waves on piles. Transactions, AIME, Volume 189.

New A.L., Magalhaes J.M., Silva da J.C.B., 2013. Internal solitary waves on the Saya de Malha bank of the Mascarene Plateau: SAR observations and interpretation. Deep Sea Research Part I: Oceanographic Research Papers. 79:50-61. http://dx.doi.org/10.1016/j.dsr.2013.05.008.

Osborne A.R., Burch T.L., 1980. Internal solitons in the Andaman Sea. Science, Number 4443. 208: 451-460. http://dx.doi.org/10.1126/science.208.4443.451.

Patel M.H., Jesudasen A.S., 1987. Theory and model tests for the dynamic response of free hanging risers. Journal of Sound and Vibration, 112(1): 149-166. http://dx.doi.org/10.1016/S0022460X(87)80099-8.

Pu B., Huang T., Wen C., 2014. A preconditioned and extrapolationaccelerated GMRES method for PageRank. Applied

Mathematics Letters. 37: 95-100. http://dx.doi.org/10.1016/j.aml.2014.05.017.

Qi M., Li L., Song L., et al., 2015. Configuration and operation optimization of deepwater drilling riser considering of evacuation due to typhoon. ISOPE-I-15-457.

Royer B. S., Power T.L., Ayewah D.O., et al., 2014. Assessment of ultra deepwater riser concepts for high-motion vessels. OTC25297-MS. http://dx.doi.org/10.4043/25297-MS.

Saad Y., Schultz M.H., 1986. GMRES: A generalized minimal residual algorithm for solving nonsymmetric linear systems. SIAM Journal on Scientific and Statistical Computing, 7(3): 856-869. http://dx.doi.org/10.1137/0907058.

Sexton R.M., Agbezuge L.K., 1976. Random wave and vessel motion effects on drilling riser dynamics. OTC-2650-MS. http://dx.doi.org/10.4043/2650-MS.

Si Z., Zhang Y., Fan Z., 2012. A numerical simulation of shear forces and torques exerted by large-amplitude internal solitary waves on a rigid pile in South China Sea. Applied Ocean Research. 37: 127-132. http://dx.doi.org/10.1016/j.apor.2012.05.002.

Song Z.J., Teng B., Gou Y., et al., 2011. Comparisons of internal solitary wave and surface wave actions on marine structures and their responses. Applied Ocean Research. 33:120-129. http://dx.doi.org/10.1016/j.apor.2011.01.003.

Wang J., Fu S., Baarholm R., et al., 2014. Fatigue damage of a steel catenary riser from vortex-induced vibration caused by vessel motions. Marine Structures. 39: 131-156. http://dx.doi.org/10.1016/j.marstruc.2014.07.002.

Wang J., Fu S., Baarholm R., et al., 2015. Out-of-plane vortexinduced vibration of a steel catenary riser caused by vessel motions. Ocean Engineering. 109: 389-400. http://dx.doi.org/10.1016/j.oceaneng.2015.09.004.

Wang Y., Gao D., Fang J., 2014. Static analysis of deep-water marine riser subjected to both axial and lateral forces in its installation. Journal of Natural Gas Science and Engineering. 19: 84-90. http://dx.doi.org/10.1016/j.jngse.2014.04.019.

Wang Y., Gao D., Fang J., 2015. Study on lateral vibration analysis of marine riser in installation-via variational approach. Journal of Natural Gas Science and Engineering. 22: 523-529. http://dx.doi.org/10.1016/j.jngse.2014.12.012.

Williams D., 2010. Optimization of drilling riser operability envelopes for harsh environments. OTC-20775-MS. http://dx.doi.org/10.4043/20775-MS.

Wu W., Wang J., Tian Z., et al., 2014. Dynamical analysis on drilling riser evacuated in hard hang-off mode. ISOPE-I-14-189.

Xie J., Jian Y., Yang L., 2010. Strongly nonlinear internal soliton load on a small vertical circular cylinder in two-layer fluids. Applied Mathematical Modelling. 34: 2089-2101. http://dx.doi.org/10.1016/j.apm.2009.10.021.

Xie J., Xu J., Cai S., 2011. A numerical study of the load on cylindrical piles exerted by internal solitary waves. Journal of Fluids and Structures. 27: 1252-1261. http://dx.doi.org/10.1016/j.jfluidstructs.2011.04.007.

Xu J., Chen Z., Xie J., et al., 2016. On generation and evolution of seaward propagating internal solitary waves in the northwestern South China Sea. Communications in Nonlinear Science and Numerical Simulation. 32: 122-136. http://dx.doi.org/10.1016/j.cnsns.2015.08.013.

Zhao L., Ouyang J., Zhou W., et al., 2015. The simpler GMRES method combined with finite volume method for simulating viscoelastic flows on triangular grid. Advances in Engineering Software. 87: 57-67. http://dx.doi.org/10.1016/j.advengsoft.2015.05.001.

Zha G., He Y., YuT., et al., 2012. The force exerted on a cylindrical pile by ocean internal waves derived from nautical X-band radar observations and in-situ buoyancy frequency data. Ocean Engineering. 41: 13-20. http://dx.doi.org/10.1016/j.oceaneng.2011.12.014. 


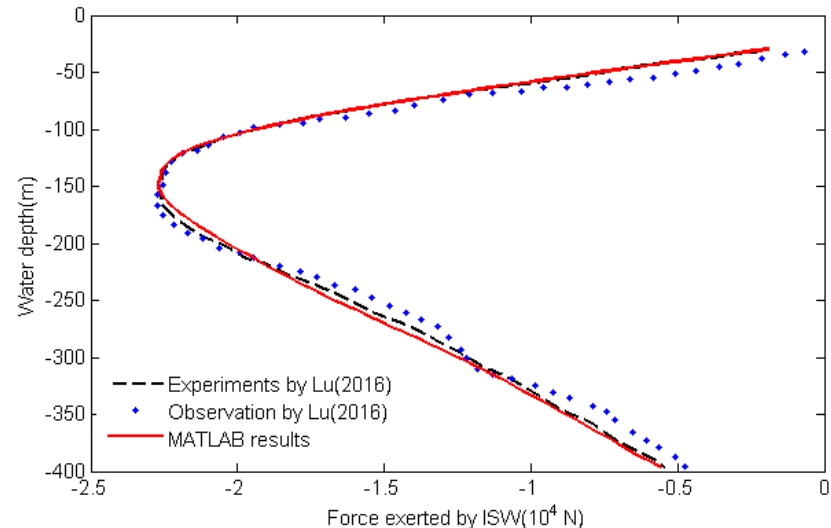

(a)

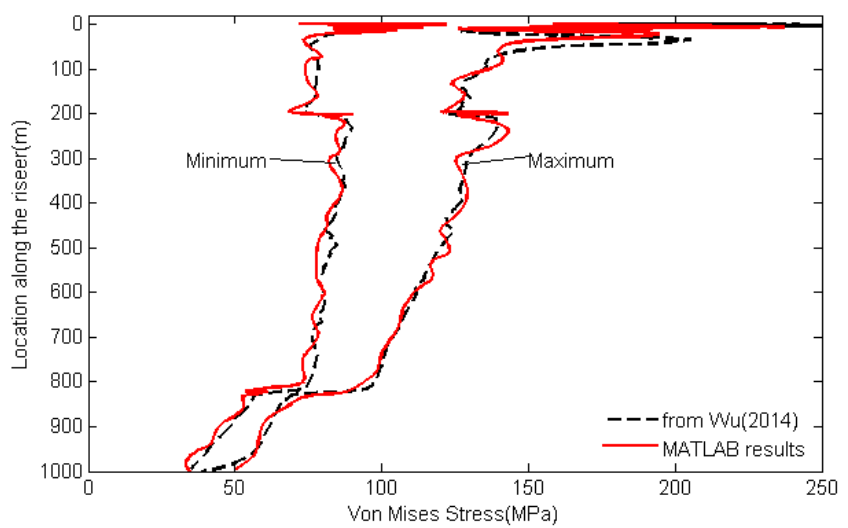

(b)

Fig. 3. Verification of the method and program by comparing to the results of other papers
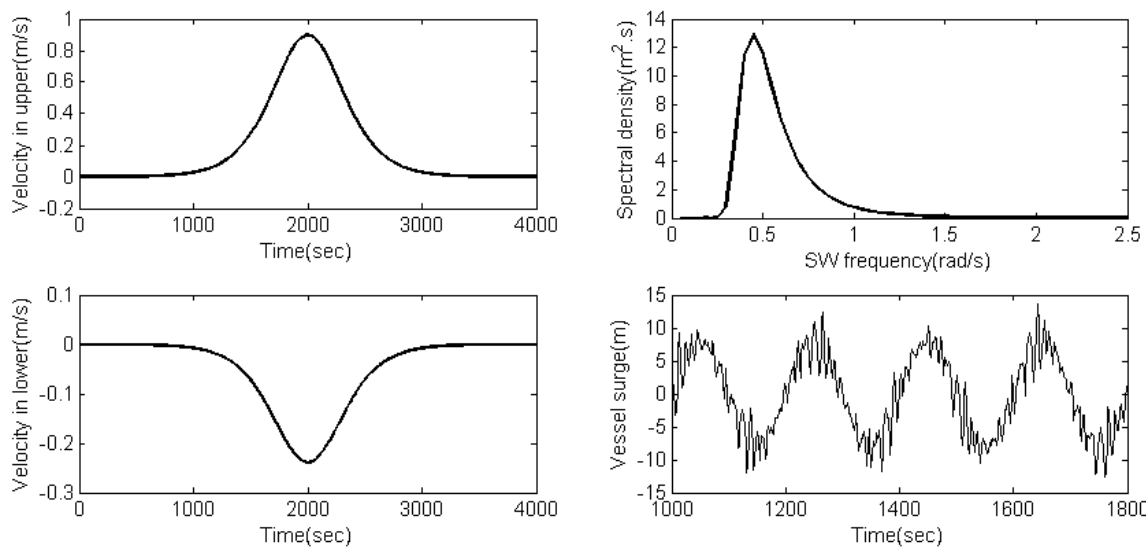

(b)P-M spectrum \& Vessel surge

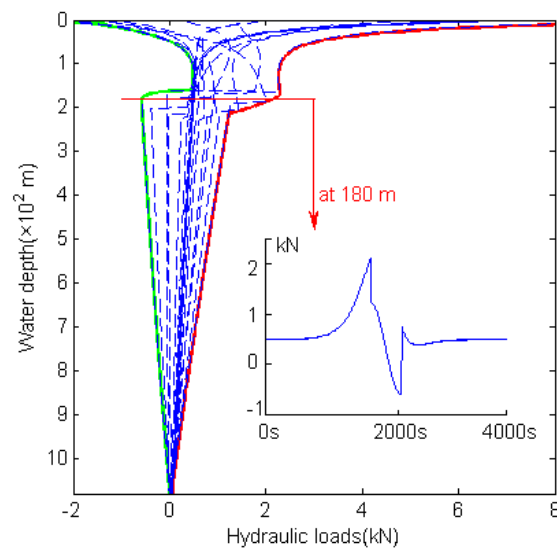

(c) Combined hydraulic loads $(\mathrm{OC}+\mathrm{SW}+\mathrm{M})$

Fig. 4. Calculation results of the preliminary parameters

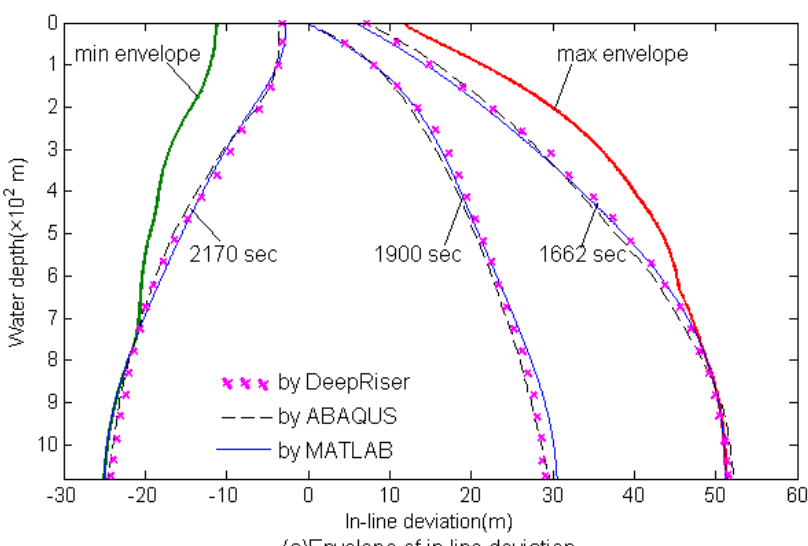

(a)Envelope of in-line deviation

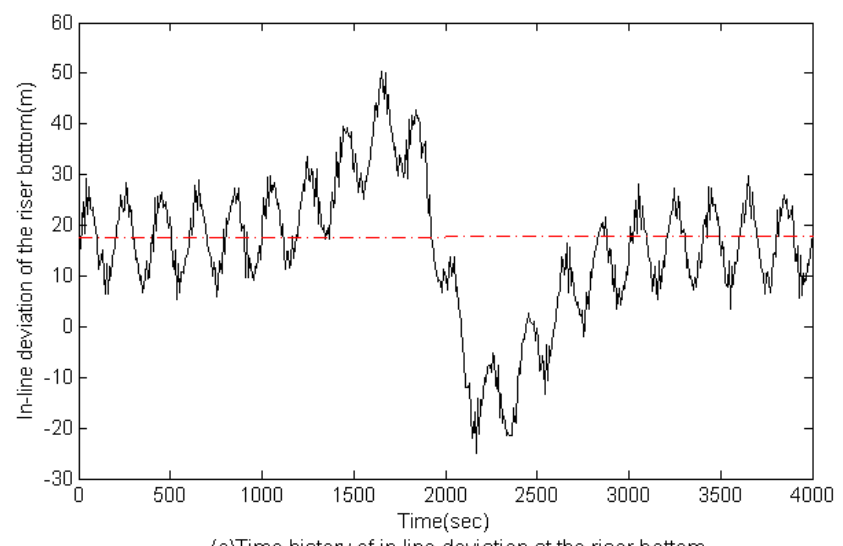

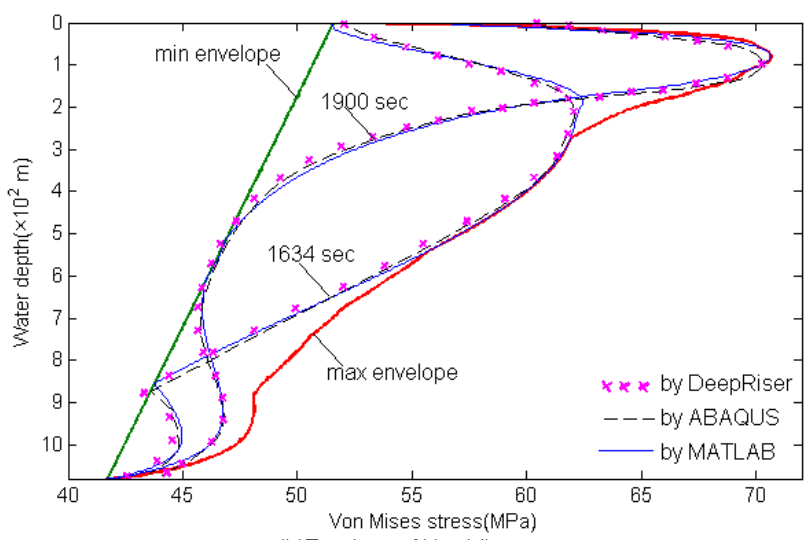

(b)Envelope of Von Mises stress

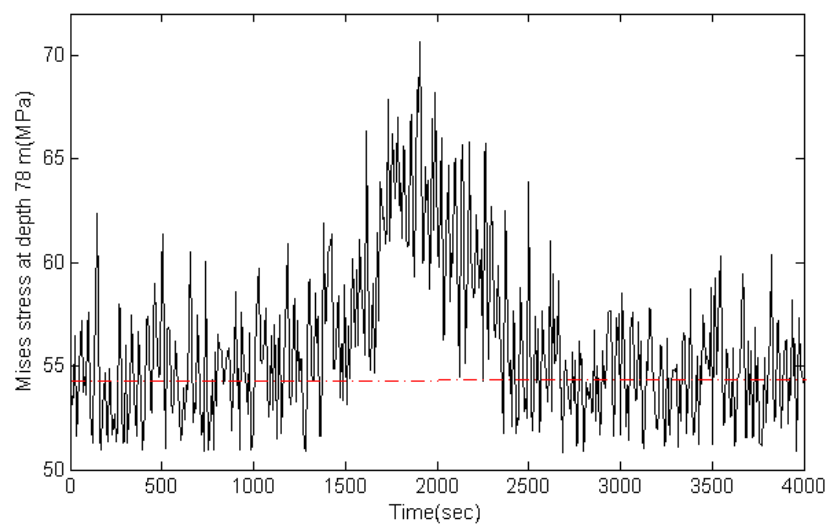

(d)Time history of Von Mises stress at depth $78 \mathrm{~m}$

Fig. 5. Riser responses under combined loads (Soft, R+LMRP, OC+SW+IW+VS) 


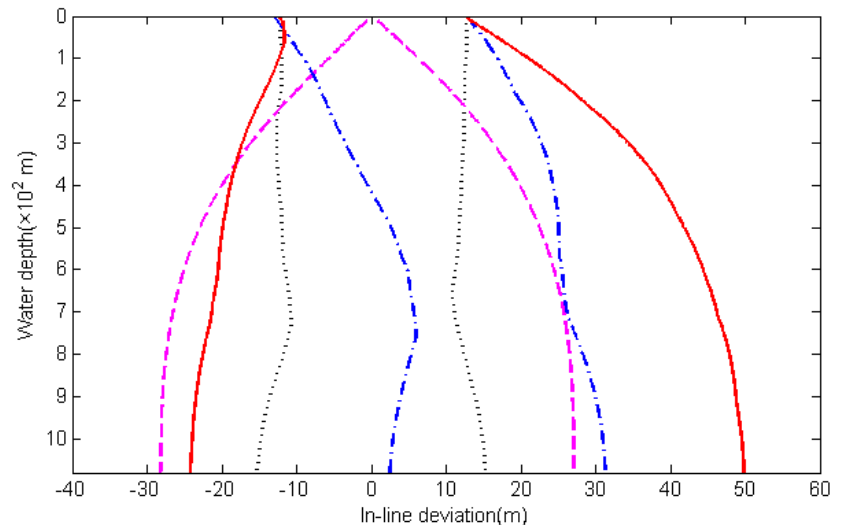

(a)

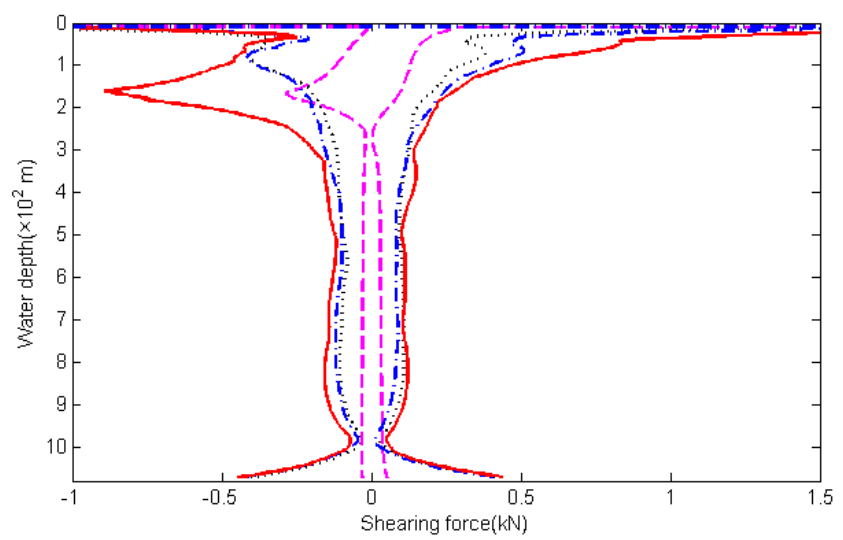

(c)

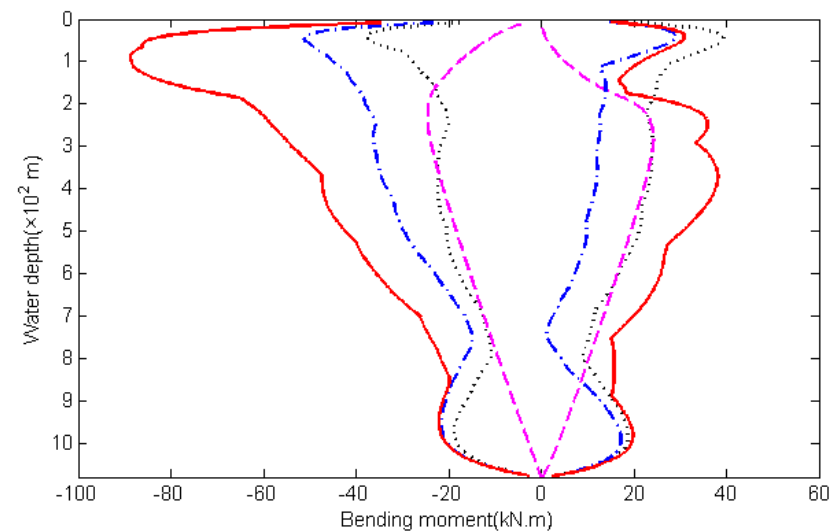

(b)

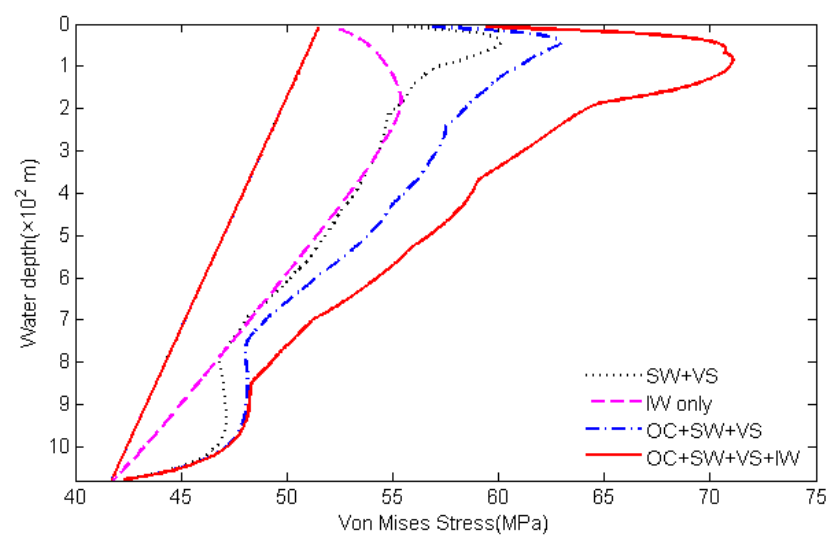

(d)

Fig. 6. Envelopes of the riser properties under different loads (Soft, R+LMRP)
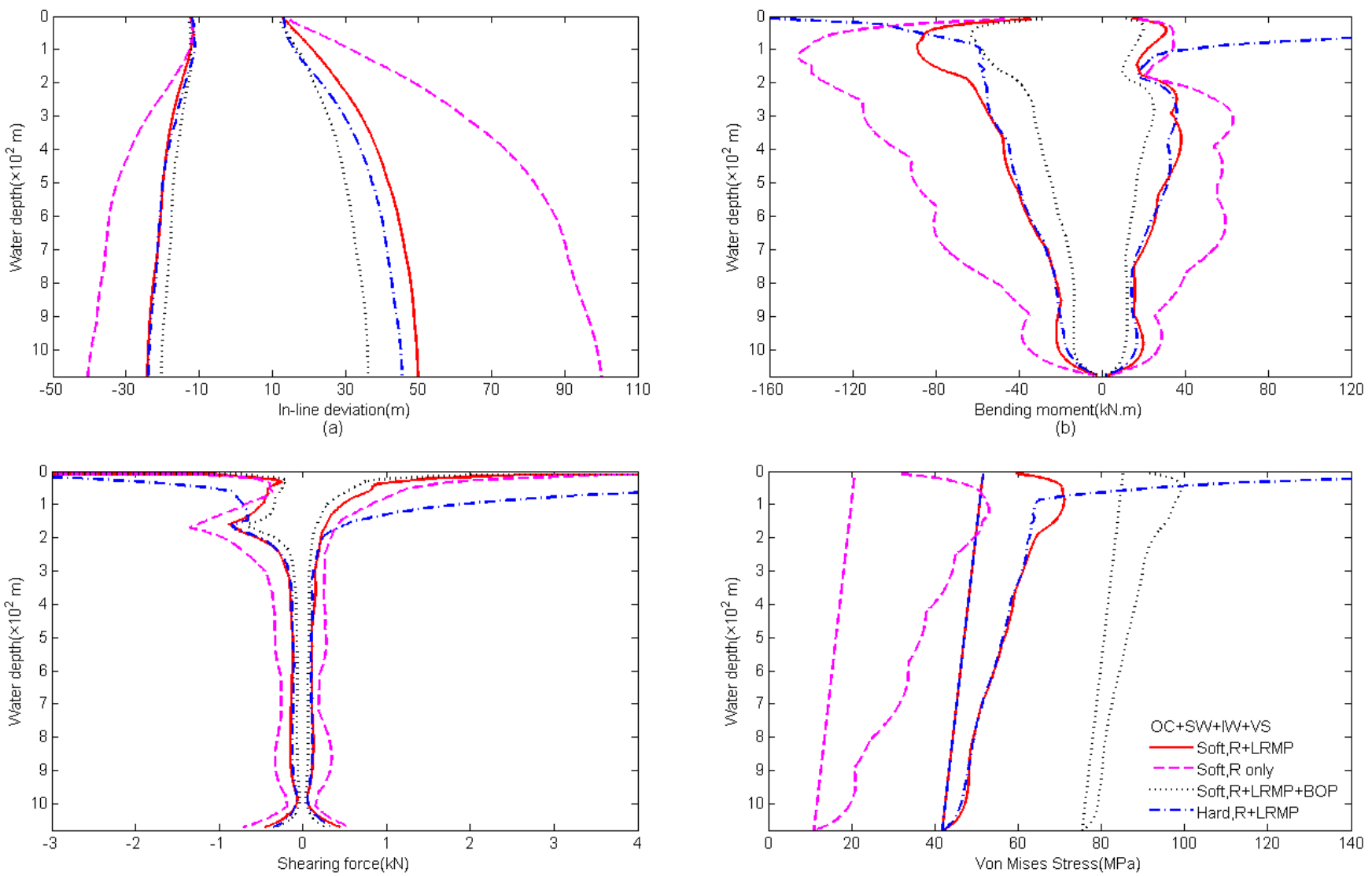

(c)

(d)

Fig. 7. Envelopes of the riser properties with different hang-off modes $(\mathrm{OC}+\mathrm{SW}+\mathrm{IW}+\mathrm{VS})$ 

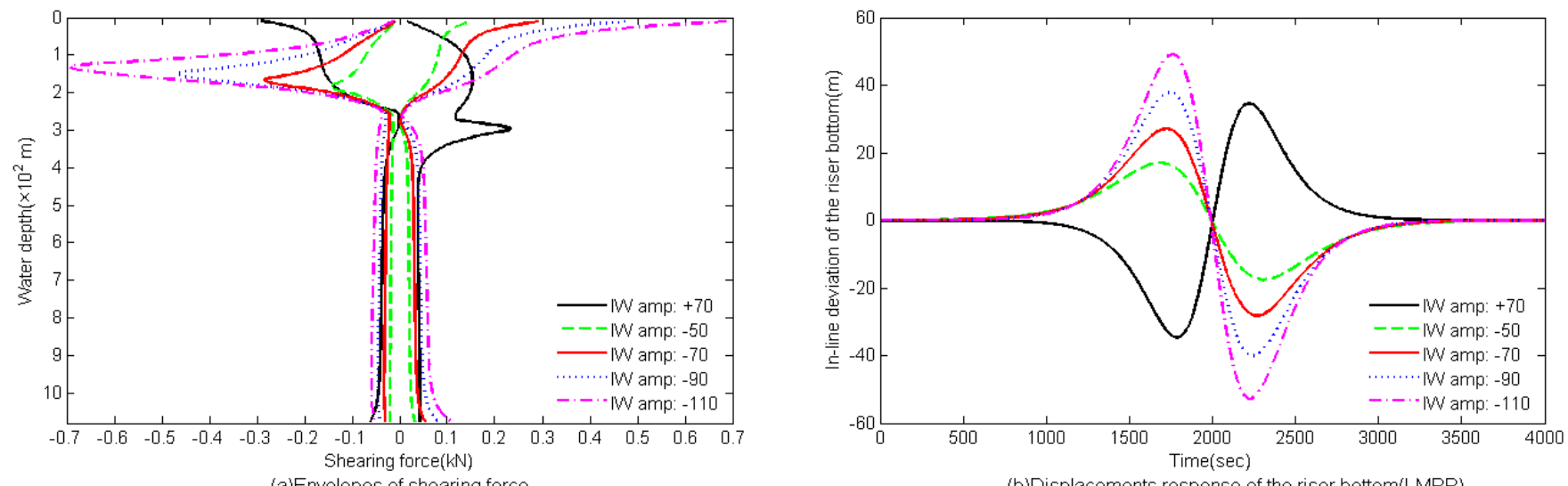

a) Envelopes of shearing force
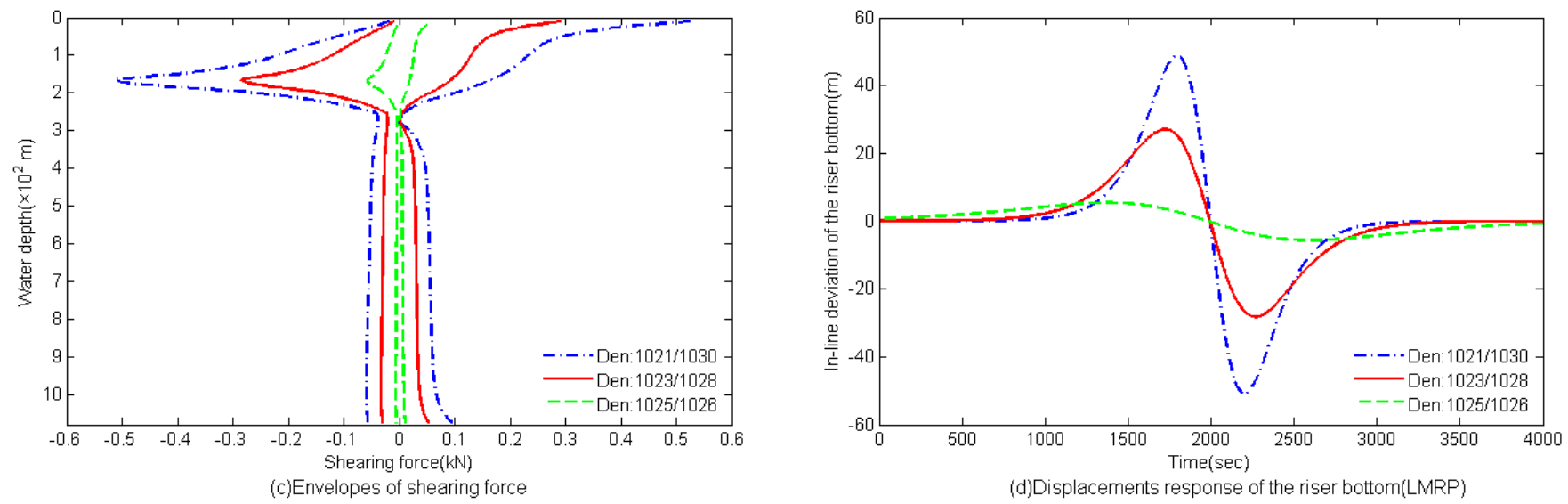

(d)Displacements response of the riser bottom(LMRP)

Fig. 8. Riser properties with different ISW parameters (Soft, R+LMRP, OC+SW+IW+VS)

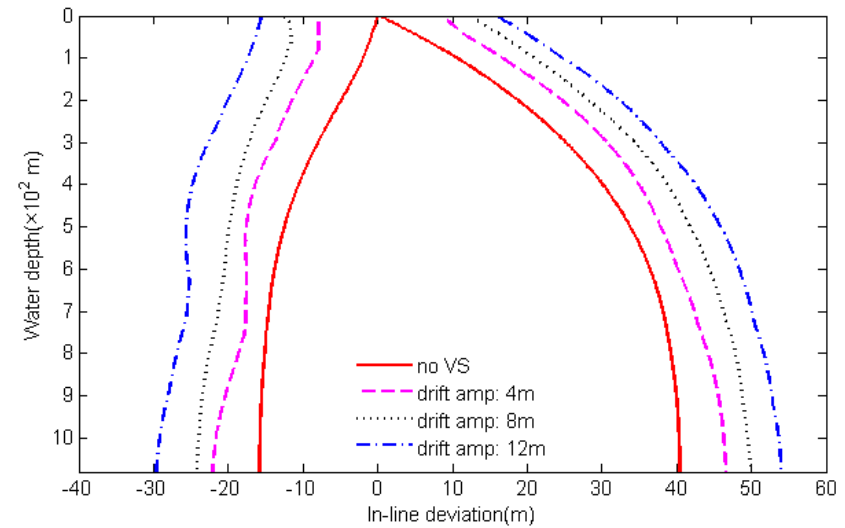

(a)!n-line deviation with different vessel drift amplitude

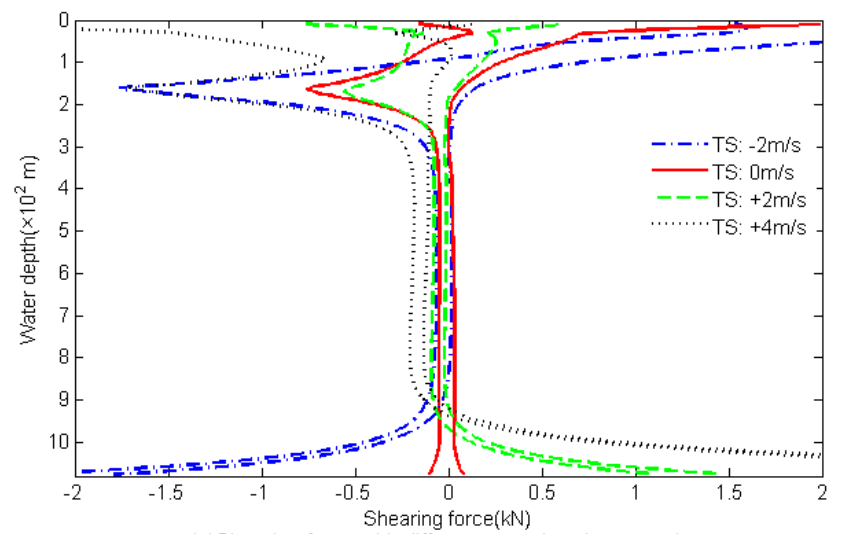

(c) Shearing force with different vessel towing speed

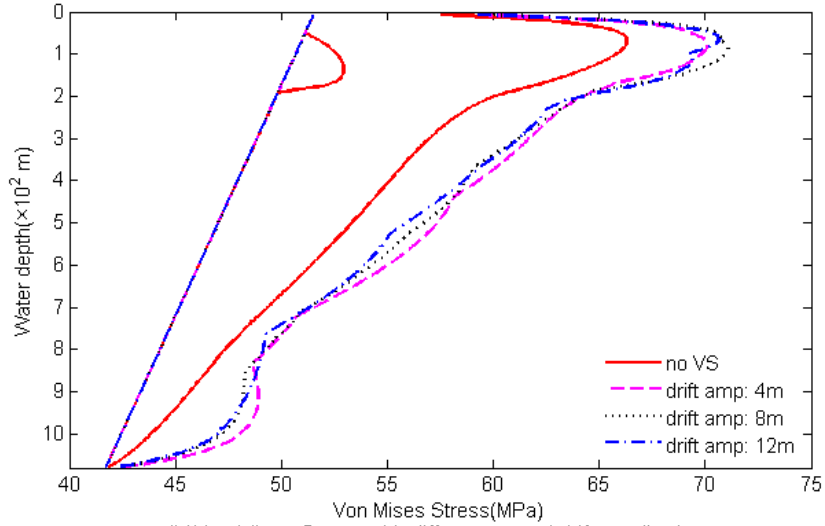

(b)Von Mises Stress with different vessel drift amplitude

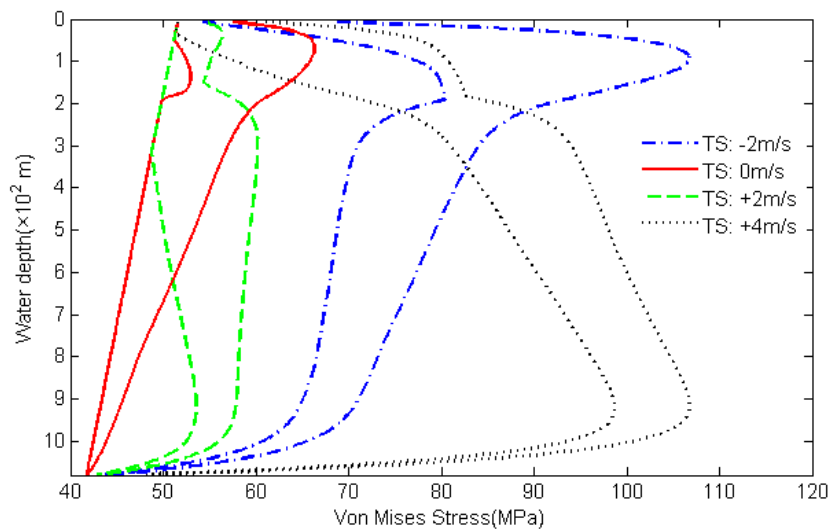

(d) Von Mises Stress with different vessel towing speed

Fig. 9. Riser properties with different vessel motion parameters (Soft, R+LMRP, OC+SW+IW+VS) 